\title{
Less Than Partial Response in cGVHD
}

National Cancer Institute

\section{Source}

National Cancer Institute. Less Than Partial Response in CGVHD. NCI Thesaurus. Code C103141.

Change towards improvement from the pretreatment baseline, but not meeting the criteria for Complete Response or Partial Response in chronic Graft versus Host Disease (cGVHD). 